\section{Revista Chilena \\ de Pediatría}

wWw.revistachilenadepediatria.cl

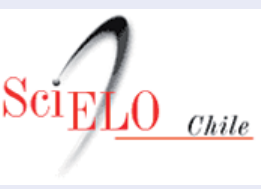

www.scielo.cl

\title{
La nueva ola de inmigración en Chile. Oportunidad para crecer como país
}

\author{
The new inmigration wave in Chile. \\ An opportunity for growing
}

\author{
Rodrigo Vásquez-De Kartzow ${ }^{\mathrm{a}}$ \\ aPediatra Infectólogo. Departamento de Pediatría y Cirugía Infantil Campus Centro. \\ Grupo de trabajo Migración y Salud, Facultad de Medicina, Universidad de Chile
}

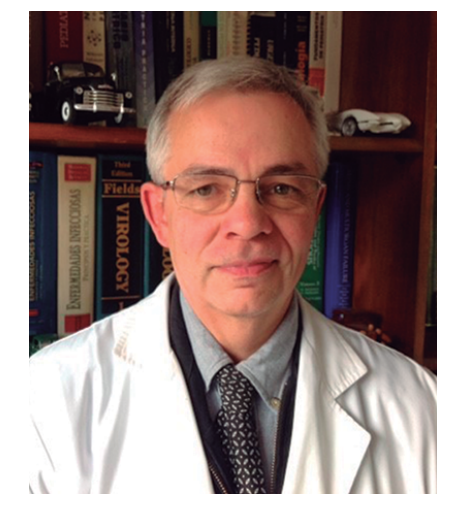

Se agradece que revistas científicas de la importancia que tiene la Revista Chilena de Pediatría se ocupe de un tema tan relevante para el Chile actual. Tema transversal que debe analizarse desde diferentes puntos de vista. Impacto en salud, impacto en la economía en el país de origen y de acogida, impacto demográfico, epidemiológico, impacto cultural, nutricional, etc.

En la medida que se conozca el fenómeno de las migraciones podremos comprender la oportunidad que se nos presenta.

Artículos como el de Cabieses B y colaboradores ${ }^{1}$ que se refiere a la brecha de desigualdad en salud entre niños migrantes en comparación con niños chilenos reflejan que la academia ha tomado un rol importante en la discusión. Es indispensable transparentar las situaciones de vulnerabilidad social que, con mucha frecuencia, padecen las comunidades de inmigrantes internacionales para poder plantear soluciones que permitan la mejor y más rápida inserción a esta nueva sociedad y con el menor trauma posible.

Una de las comunidades que merece toda nuestra atención es la haitiana, la cual ha tenido un crecimiento rápido en muy poco tiempo. Se calcula que en 2017 ingresaron a Chile en promedio 4.307 personas/ mes principalmente jóvenes entre 15 y 30 años. Es indispensable que frente a esta reciente ola migratoria proveniente de Haití nos ocupemos en entender sus costumbres, idioma, nutrición, formas de concebir la salud y la enfermedad, padecimientos más frecuentes como por ejemplo, la anemia de células falciformes que hasta hace algún tiempo era prácticamente desconocida en Chile. Cuando se publican artículos como el de Barrera $\mathrm{F}$ y colaboradores ${ }^{2}$ que nos invitan a conocer los aspectos culturales, de crianza y salud de inmigrantes haitianos en Chile se contribuye desde la academia a buscar puntos de encuentro entre comunidades tan disimiles pero que comparten cosas en común. Cuando logremos entender que la diferencia complementa y no separa, habremos crecido como sociedad.

En el contexto de la migración, salud significa el bienestar físico, mental y social de los migrantes y de las poblaciones en desplazamiento ${ }^{3}$.

El término migrante abarca usualmente todos los casos en los que la decisión de migrar es tomada libremente por la persona concernida por "razones de conveniencia personal" y sin intervención de factores externos que le obliguen a ello. Así, este término se aplica a las personas y a sus familiares que van a otro país o región con miras a mejorar sus condiciones sociales y materiales y sus perspectivas y las de sus familias. A diferencia del desplazado, quien es una persona que ha tenido que abandonar su país o región debido a persecución, violencia generalizada, violación masiva de derechos humanos, conflictos armados u otras situaciones de esta naturaleza. Estos individuos huyen, 
a menudo, en masa. A veces también se les denomina "refugiados de facto".

El número de migrantes internacionales (personas que viven en un país diferente al de su nacimiento) alcanzó la cifra de 244 millones en 2015 equivalente al $3,3 \%$ de la población mundial y se estima que 9 millones viven en la región de América Latina y el Caribe, según datos publicados por Naciones Unidas ${ }^{4}$.

Hasta hace algunos años, los flujos migratorios eran más o menos constantes, desde los países considerados menos desarrollados o subdesarrollados hacia los países desarrollados. (Migración Norte-Sur), pero como consecuencia de la recesión mundial de 2007, estos flujos han derivado en cambios sustanciales, tomando una gran relevancia los movimientos hacia países con economías emergentes (Migración Sur-Sur) cuyo ejemplo podría ser la reciente y constante migración desde países de la región hacia el Cono Sur ${ }^{5}$.

La idea de un país lejano, aislado y de difícil acceso ha quedado en el pasado. En pocos años, Chile ha pasado de ser un país de emigrantes a ser un país de inmigrantes con una Tasa Neta de Migración positiva de $0,3^{6}$.

Chile se ha embarcado en un viaje sin retorno. Un viaje que traerá nuevas oportunidades de crecimiento y desarrollo si somos capaces de aprovechar esta nueva ola de inmigración. En los últimos 35 años la migración hacia Chile se ha sextuplicado pasando de 0,7\% en 1982 al 4\% en 2017 y se estima que para el año 2020 se alcanzaría la cifra de 1 millón de extranjeros en el país. Sin embargo, aún estamos muy por debajo del promedio de los 35 países miembros de OCDE que es del $13 \%{ }^{7}$. La población infantil alcanza el $12 \%$ del total de inmigrantes pero la cifra aumenta si sumamos a los hijos de inmigrantes nacidos en Chile lo que se ha conocido como "el nuevo rostro de Chile".

La legislación migratoria en Chile ha evolucionado lentamente desde la prohibición de ingreso a los europeos en general con excepción de los españoles en 1817, pasando por la ley 3.446 de 1918 la cual impedía el ingreso a territorio nacional de "elementos indeseables", seguido por la ley DFL 69 de abril de 1953 la cual planteaba un plan inmigratorio para la "mejora biológica de la raza chilena" y llegando a la actual ley de migraciones 1.094 de 1975 en que se plantea que la inmigración debe tener una lógica de seguridad nacional la cual probablemente para esos tiempos era adecuada, pero que no se ajusta a la realidad actual quedando obsoleta en establecer los derechos y deberes de las comunidades de inmigrantes, entre otras falencias ${ }^{7}$.

La migración y la salud están relacionadas y son interdependientes. Por cierto, muchas de las desigualdades que dan lugar a la propagación mundial de las enfermedades también dan lugar a la migración. Como ejemplo claro de infecciones agudas podemos recordar el éxodo masivo de personas producto del brote del Síndrome Respiratorio Agudo Severo (SARS) en 2003 en el cual más de un millón de personas abandonaron Pekín o más recientemente la epidemia de Ébola en África occidental en 2014 que ha afectado a la fecha a más de 10 países de diferentes continentes.

Como es habitual, es en el sector marginal de los pueblos donde las epidemias se ensañan debido al alto costo para su curación y mayor frecuencia de resistencia a los tratamientos establecidos, lo que convierte una enfermedad completamente prevenible y curable como podría ser la tuberculosis en una enfermedad de muy difícil y costoso tratamiento ${ }^{8,9}$.

La llegada de extranjeros al país receptor no implica per se un riesgo mayor de un cambio en la epidemiología local, en la medida que los programas de vigilancia epidemiológica funcionen correctamente y que el personal de salud que atiende a pacientes inmigrantes esté alerta a la detección de ciertas patologías poco comunes o desconocidas en el país. Al respecto, se recomienda que el niño inmigrante tenga una primera evaluación médica en centros de atención primaria lo más cercano a su llegada al país. Esta atención tendría varios objetivos, entre ellos el dar a conocer cómo funciona el sistema de salud en Chile, cuya base es la atención primaria. Es conocido que muchas comunidades extranjeras consultan más a los Servicios de Urgencia que a la atención primaria. Otro objetivo es conocer su situación de salud al llegar al país, haciendo énfasis en revisar su documento de vacunación y no solamente el esquema de cada país porque sabemos que hay países vecinos con mejor esquema de vacunación pero con una muy baja cobertura.

Uno de los factores que han contribuido al interés emergente de la salud migratoria es que los sistemas de salud en los países deben responder a las nuevas necesidades de atención de acuerdo a los patrones de la movilidad de las poblaciones ${ }^{10,11}$.

Los inmigrantes en los países de acogida, especialmente en situación irregular, tienen una dificultad mayor para el acceso al sistema de salud, aunque se han hecho esfuerzos en varios países receptores para que ello no ocurra. Tal es el caso de Chile en que se permite el acceso al Fondo Nacional de Salud FONASA mientras dure el proceso de solicitud de visa, periodo que puede ser prorrogable lo cual permite tener los mismos beneficios de salud que el resto de la población autóctona. Igualmente se ha favorecido a grupos con mayor vulnerabilidad como los niños menores de 18 años de edad y embrazadas, los cuales tienen acceso libre a la atención de salud y todos los beneficios sociales que ello conlleve, independiente de su situación migratoria $^{12}$.

Para avanzar hacia una sociedad más justa e incluyente es necesario desmitificar algunas frases cliché que 
poco y nada colaboran con la inserción y aceptación de este nuevo Chile como por ejemplo: los migrantes nos quitan el trabajo o ha aumentado la delincuencia como consecuencia de la migración o que ha aumentado la pobreza en este grupo de nuevos chilenos. Nada más alejado de la realidad. La encuesta CASEN 2015 ha demostrado que los inmigrantes en rango de pobreza no superan a la población autóctona en ese rango de pobreza. Tienen un nivel promedio de escolaridad superior al nivel de la población chilena y en cuanto a la delincuencia las cifras muestran que el 1,2\% de los detenidos e imputados en 2015 eran extranjeros frente al 2,3\% de los chilenos. Frente al argumento que los inmigrantes están saturando los servicios de salud, las cifras de la encuesta CASEN 2015 nuevamente demuestran que solo el 0,4\% de los egresos hospitalarios corresponden a extranjeros y el 18\% de los extranjeros está afiliado a Isapres frente al 15\% de los nacionales ${ }^{13}$.

En la actualidad, la inserción del inmigrante en nuestro país es muy compleja. La mayoría de ellos migran para obtener mejores condiciones laborales, de seguridad y sociales que el que tenían en sus países de origen, sin embargo, no siempre lo encuentran o existe un periodo de latencia variable hasta conseguir lo que desean. Lo anterior, debido a las precarias condiciones estructurales y socioeconómicas que producen un empobrecimiento en las personas con repercusiones en la disminución del bienestar biopsicosocial que tenían en el país de origen y el consecuente deterioro de la sa$\operatorname{lud}^{14}$. Estos factores contribuyen a que estas personas queden en una situación de vulnerabilidad social. Se suman además, condiciones de vulnerabilidad personal, especialmente cuando experimentan la enfermedad en un contexto que les es ajeno y donde, además, hay falta de soporte social y sufrimiento asociado a la exclusión. Es ahí donde se hace evidente la falta de recursos del migrante para recuperar su estado de salud. Cuando la persona se enferma, intenta mejorar su salud utilizando los marcos de referencia y recursos que le son familiares y que les proporcionan conocimiento acerca de cómo enfrentar la enfermedad. Para un creciente número de personas inmigrantes, este apoyo desaparece una vez están en el país de acogida, donde la mantención de la salud no siempre es posible.

Pienso que la oportunidad que tenemos con la inmigración será una de las claves para salir del subdesarrollo económico y social. La riqueza cultural, gastronómica, lingüística, etc. sólo traerá beneficios para este país cada vez más cercano con la realidad mundial, pero depende de nosotros el saber aprovechar este fenómeno. Con la migración ganamos todos.

\section{Conflicto de intereses}

El autor declara no tener conflicto de intereses.

\section{Referencias}

1. Cabieses B, Chepo M, Galvez MDPO, Markkula N, Bustos P, Pedrero V, Delgado I. Brechas de desigualdad en salud en niños migrantes versus locales en Chile. Rev Chil Pediatr 2017;88(06):70716.

2. Sánchez K, Valderas J, Messenger KPM, Sánchez C, Barrera FJ. Haití, la nueva comunidad inmigrante en Chile. Rev Chil Pediatr 2018;89(2). En prensa.

3. Organización Internacional para las Migraciones; Derecho Internacional sobre Migraciones. Glosario sobre Migraciones. 2006. Disponible en: http:// publications.iom.int/bookstore/free/ IML_7_SP.pdf

4. United Nations, Department of Economic and Social Affairs, Population Division. Trends in International Migration, POPFACTS 2015(4):1-4.

5. Cabieses B, Tunstall H, Pickett KE, Gideon J. Changing patterns of migration in Latin America: how can research develop intelligence for public health? Rev Panam Salud Publica 2013; 34(1):6874.
6. Vásquez-De Kartzow R, Castillo-Durán C, Lera L. Migraciones en países de América Latina. Características de la población pediátrica. Rev Chil Pediatr 2015;86(5):325-30.

7. Departamento de Extranjería y Migraciones. Ministerio de Interior. Gobierno de Chile. [Consultado el 25 de mayo de 2016] Disponible en: http://www.extranjeria.gob.cl/ noticias/2016/05/26/expertos-coincidenla-migracion-es-un-aporte-para-el-pais/

8. Vásquez-De Kartzow R. Impacto de las migraciones en Chile. Nuevos retos para el pediatra. ¿Estamos preparados? Rev Chil Pediatr 2009;80(2):161-7.

9. Vásquez-De Kartzow R. Viejos y nuevos actores de la epidemiología en tiempos de globalización. Rol de los inmigrantes. En: Migraciones, salud y globalización: Entrelazando miradas. OIM, Ministerio de Salud, OPS. Santiago, Chile. 2010: 2536.

10. Organización Mundial de la Salud; "Migración Internacional, Salud y Derechos Humanos"; Ginebra; 2003. [Consultado el 12 de diciembre de 2017] Disponible en: http://www.who.int/hhr/
activities/2005\%20PRT\%2016325\%20 ADD\%201\%20Migr_HHR-Spanish\%20 edition.pdf.

11. World Health Organization; "Resolution WHA 61.17: Health of Migrants"; Geneva: World Health Organization; 2008.

[Consultado el 12 de diciembre de 2017] Disponible en: http://apps.who.int/gb/ ebwha/pdf_files/A61/A61_R17-en.pdf.

12. Vásquez-De Kartzow R, Castillo-Durán C. Embarazo y parto en madres inmigrantes en Santiago, Chile. Rev Chil Pediatr 2012;83(4):359-63.

13. Encuesta Casen 2015. Ministerio de Desarrollo Social [Consultado el 15 de diciembre de 2017] Disponible en: http:// observatorio.ministeriodesarrollosocial. gob.cl/casen-multidimensional/casen/ docs/casen_nmigrantes_2015.pdf.

14. Becerra M, Altimir L. Cap. 6 El derecho a la salud de los niños y niñas migrantes y refugiados, contextos y especidad en salud mental. En ACNUR, OIM, UNICEF: Los derechos de los niños, niñas y adolescentes migrantes, refugiados y víctimas de trata internacional en Chile: Avances y desafíos. 2012;191-216. Santiago: Andros Impresores. 